\title{
ERK inhibition represses gefitinib resistance in non-small cell lung cancer cells
}

\author{
Mengfan Qi ${ }^{1,2, *}$, Ye Tian ${ }^{3,5, *}$, Wang $\mathrm{Li}^{3,5, *}$, Dan $\mathrm{Li}^{3,5}$, Tian Zhao ${ }^{3,5}$, Yuxin Yang ${ }^{3,5}$, Qiwen \\ $\mathbf{L i}^{3,5}$, Sujun Chen ${ }^{5}$, Yan Yang ${ }^{3,5}$, Zhixiong Zhang ${ }^{3,5}$, Liang Tang ${ }^{4}$, Zhonghua Liu ${ }^{1}$, Bo \\ $\mathbf{S u}^{4}$, Fei $\mathrm{Li}^{6}$, Yonghong Feng ${ }^{1}$, Ke Fei ${ }^{2}$, Peng Zhang ${ }^{2}$, Fan Zhang ${ }^{1,2,3,5}$ and Lei Zhang ${ }^{2}$ \\ ${ }^{1}$ Shanghai Key Lab of Tuberculosis, Shanghai Pulmonary Hospital, Tongji University School of Medicine, Shanghai 200433, \\ China \\ ${ }^{2}$ Department of Thoracic Surgery, Shanghai Pulmonary Hospital, Tongji University School of Medicine, Shanghai 200433, \\ China \\ ${ }^{3}$ Clinical Translational Research Center, Shanghai Pulmonary Hospital, Tongji University School of Medicine, Shanghai \\ 200433, China \\ ${ }^{4}$ The Central Laboratory, Shanghai Pulmonary Hospital, Tongji University School of Medicine, Shanghai 200433, China \\ ${ }^{5}$ School of Life Science and Technology, Tongji University, Shanghai 200092, China \\ ${ }^{6}$ Department of Biology, New York University, New York, NY 10003, USA \\ *These authors contributed equally to this work \\ Correspondence to: Lei Zhang, email:13816121971@163.com \\ Fan Zhang, email: fzhang@tongji.edu.cn \\ Keywords: non-small cell lung cancer; gefitinib resistance; ERK signaling; autophagy \\ Received: September 06, $2017 \quad$ Accepted: January 03, $2018 \quad$ Published: January 10, 2018 \\ Copyright: Qi et al. This is an open-access article distributed under the terms of the Creative Commons Attribution License 3.0 \\ (CC BY 3.0), which permits unrestricted use, distribution, and reproduction in any medium, provided the original author and source \\ are credited.
}

\section{ABSTRACT}

Gefitinib, an EGFR tyrosine kinase inhibitor, is used to treat non-small cell lung cancer (NSCLC) patients with activating EGFR mutations. However, the resistance to gefitinib eventually emerges in most of the patients. To understand its mechanism, we generated two acquired gefitinib-resistant NSCLC cell lines. The resistant cells have slower growth rates, but are more resistant to apoptosis in the presence of gefitinib, compared with their sensitive counterparts. In addition, our genome-wide transcriptome analysis reveals unexpected pathways, particularly autophagy, are dysregulated in the gefitinib-resistant cells. Autophagy is significantly enhanced in resistant cells. Importantly, inhibition of autophagy reduces gefitinib resistance. Furthermore, the phosphorylation of ERK, the extracellular signal-regulated kinase, is activated in resistant cells. Inhibition of ERK phosphorylation abrogates gefitinib resistance by suppressing autophagy both in vitro and in vivo. These findings establish a link between ERK and autophagy in gefitinib resistance, and suggest that the ERK signaling may serve as the potentially therapeutic target for treating gefitinib resistance in NSCLC patients.

\section{INTRODUCTION}

Tyrosine kinase inhibitors (TKIs), such as gefitinib and erlotinib, have been used as the first-line treatment for non-small cell lung cancer (NSCLC) patients harboring oncogenic alterations in epidermal growth factor receptor (EGFR) [1-4]. TKIs act as competitive inhibitors for ATP binding of EGFR, thus blocking cell proliferation signaling pathways, leading to apoptosis of cancer cells [5]. Although the initial clinical response and antitumor activity are encouraging, most patients eventually develop acquired resistance towards these drugs, and die due to cancer metastasis from these resistant tumor cells. Therefore, TKI resistance presents a serious challenge in NSCLC treatment. Multiple mechanisms of acquired resistance to EGFR inhibitors have been reported, including a 
secondary "gatekeeper" mutation in EGFR (T790M) [6], MET receptor gene amplification [7], the activation of TGF- $\beta$, NF- $\kappa B$, or IGFIR signaling [8-10], or the pathological transformation of NSCLC to small cell lung cancer (SCLC), etc [11-12]. However, it has been reported that unknown mechanisms might also play a role in many cases of gefitinib resistance [11].

Autophagy is induced in drug-treated tumor cells [13-17]. Autophagy is an evolutionarily conserved process that is involved in the degradation and turnover of cytoplasmic proteins and organelles in response to environmental stress. During autophagy, a doublemembraned vesicle called an autophagosome is formed, which then fuses with a lysosome to form an autolysosome. The enclosed proteins and organelles are degraded by the lysosomal enzymes and recycled to provide energy for the cells to survive. In this process, autophagy-related gene (Atg) products, such as the Atg5-Atg12-Atg16 complex and the LC3-II (Atg8-II) complex, are recruited to form the autophagosome $[18,19]$. LC3 (Atg8) is cleaved and conjugated to phosphatidylethanolamine (PE) to form the membrane-bound, lipidated LC3-II, with the help of Atg7 and Atg3 [20]. LC3-II also binds to adapter proteins, including NBR1 and SQSTM1/p62, which are involved in trafficking proteins for autophagic degradation of ubiquitinated protein aggregates [21]. SQSTM1/p62 is normally degraded during autophagy and accumulates when autophagy is impaired [22]. Autophagy has a dual role in oncogenesis. In early tumorigenesis, autophagy may serves as a tumor suppression mechanism by degrading damaged organelles and limiting cell growth [23, 24]. However, in Ras-driven cancers, autophagy promotes cell survival, maintains oxidative metabolism and promotes tumorigenesis [25]. How autophagy is regulated during gefitinib resistance in NSCLC cells is not well understood.

Besides autophagy, the extracellular signal-regulated kinase (ERK) signaling pathway also plays a role in drug resistance. ERK is activated via a pathway that involves GTP-loading of Ras and the sequential phosphorylation and activation of Raf, MEKs, and ERK [26]. ERK activation is observed in multiple cancer cells that are resistant to MEK [27] or EGFR kinase inhibitors [28]. The Raf/MEK/ERK pathway can govern drug resistance, apoptosis and the sensitivity to the targeted therapy [29].

In this study, we generated two stable gefitinibresistant NSCLC cell lines, and found that many unexpected cellular pathways are dysregulated in these cells. In particular, autophagy was induced in gefitinibresistant cells. Inhibition of autophagy reduced the growth of resistant cells. Furthermore, resistant cells exhibited persistent ERK and AKT activation. Importantly, we showed, for the first time, that the inhibition of ERK greatly suppressed autophagy-induced gefitinib resistance both in vitro and in vivo. Therefore, our study establishes the novel link between the ERK signaling and autophagy in gefitinib resistance, and suggests the ERK signaling may serve as the potential therapeutic target for the treatment of gefitinib resistance in NSCLC patients.

\section{RESULTS}

\section{Characterization of gefitinib-resistant NSCLC cells}

To establish gefitinib-resistant cell lines, we subcutaneously injected the gefitinib-sensitive cells PC9 and HCC827 into the armpit of mice (Supplementary Figure 1A). When the xenograft tumor became visible 4 weeks later, $3 \mu \mathrm{M}$ gefitinib was intraperitoneally administered to the mice twice per week. The tumor size was measured and recorded every week (Supplementary Figure 1B). At week 10 , the gefitinib-resistant tumor was isolated, dissected into smaller pieces, and grown in culture dishes for 4 more weeks to establish the gefitinib-resistant NSCLC cell lines: PC9/GR and HCC827/GR (Supplementary Figure 1C).

To determine the $\mathrm{IC}_{50}$ of gefitinib for these cells, we cultured these cells with different concentrations of gefitinib, and carried out cell survival assays. We found there were significant difference in $\mathrm{IC}_{50}$ of gefitinib between gefitinib-sensitive and-resistant cells: $0.048 \mu \mathrm{M}$ for PC9, $0.048 \mu \mathrm{M}$ for HCC 827 cells, $13.45 \mu \mathrm{M}$ for PC9/GR cells, and $21.49 \mu \mathrm{M}$ for HCC827/GR cells (Figure 1A).

Next, these cells were assessed for their colony formation ability in the presence of increasing concentrations of gefitinib $(0,1,3,5,10 \mu \mathrm{M})$. We found that both PC9/GR and HCC827/GR cells had a stronger colony formation ability compared with their gefitinibsensitive counterparts, PC9and HCC827 cells (Figure 1B). Most of the sensitive cells had no colony formation in the presence of $1 \mu \mathrm{M}$ gefitinib, but most of the resistant cells were able to form colonies in the presence of $10 \mu \mathrm{M}$ gefitinib. This observation demonstrates the clonogenic outgrowth capacity of the resistant cells is much stronger than their sensitive counterparts.

To understand whether this discrepancy is due to their resistance to apoptosis, we performed flow cytometry assays using the early and late apoptosis markers, Annexin $\mathrm{V}$ and PI, respectively, to detect the extent of apoptosis. Our data showed that, in the presence of 0,3 , and $10 \mu \mathrm{M}$ of gefitinib for 2 days, $1 \%, 8 \%$, and $20 \%$ of PC9 cells, and $1 \%, 18 \%$, and $26 \%$ of HCC 827 cells, became apoptotic (Figure 1C), indicating that gefitinib treatment induces apoptosis in the gefitinib-sensitive cells. However, the percentage of apoptotic cells didn't increase for the resistant cells at all, which remained at approximately $1 \%$ for PC9/GR cells and 5\% or less for HCC827/GR cells, for increasing amounts of gefitinib treatments. These results indicate that gefitinib-resistant cells are resistant to apoptosis under the gefitinib treatment.

To compare the proliferation rate between the gefitinib-sensitive and -resistant cells, we performed cell 
proliferation assay, and found that PC9/GR and HCC827/ GR cells grew considerably slower in the presence of $3 \mu \mathrm{M}$ gefitinib (labeled as G+) than PC9 and HCC827 cells. Upon withdrawing the gefitinib treatment (labeled as G-), HCC $827 / \mathrm{GR}$ cells were able to recover the proliferation rate more rapidly than the $\mathrm{PC} 9 / \mathrm{GR}$ cells (Figure 1D). To understand whether the slow proliferation rate was due to changes in cell cycle progression, we found that the percentage of cells in G1 phase increased from $43 \%$ in PC9 cells to $63 \%$ in PC9/GR cells, but those in G2 and M phases decreased from 33\% in PC9 cells to $21 \%$ in PC9/GR cells in average (Figure 1E). Similarly, the percentage of cells in G1 phase increased from 53\% in HCC 827 cells to $64 \%$ in HCC $827 /$ GR cells, but those in G2 and M phases decreased from $27 \%$ in HCC 827 cells to $20 \%$ in HCC $827 /$ GR cells in average (Figure 1E).

These data indicate that PC9/GR and HCC827/GR cells have much higher $\mathrm{IC}_{50}$ of gefitinib than their sensitive counterparts, which is consistent with their stronger antiapoptotic ability. In addition, the slow proliferation rate of PC9/GR and HCC827/GR cells was due to their increased presence in G1 phase and decreased presence in G2 and M phases during the progression of the cell cycle.

\section{Transcriptome analysis of gefitinib-resistant cells}

To determine what pathways are dysregulated in gefitinib-resistant cells, we generated two sets of mRNASeq data to compare the transcriptomes of PC9 and PC9/ GR cells using two independent biological replicates. Gene expression was quantified in rpkm (reads per kilobase of exon per million mapped sequence reads) (Supplementary Table 3). Next, GFOLD was used to rank the differentially expressed genes from our RNA-Seq data. The GFOLD value can be considered as a reliable log2-fold change [30]. The heatmap clustering analysis
A
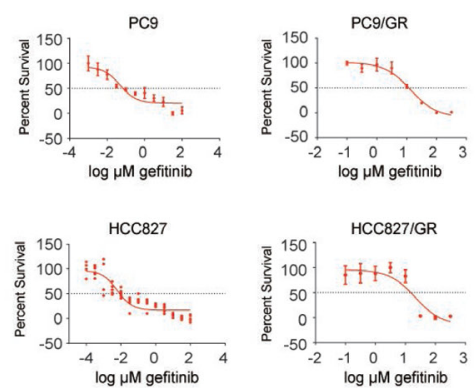

\begin{tabular}{|c|c|c|c|c|}
\hline & PC9 & HCC827 & PC9/GR & HCC827/GR \\
\hline IC $_{50}(\mu \mathrm{M})$ & 0.048 & 0.006 & 13.45 & 21.49 \\
\hline
\end{tabular}

D
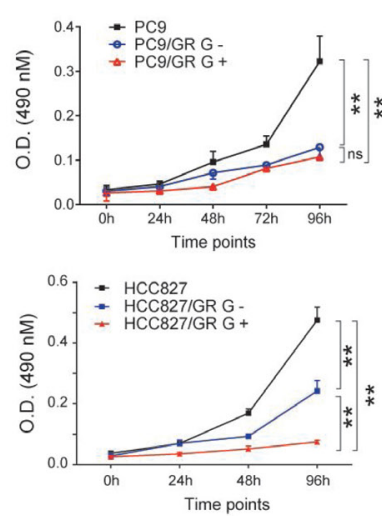

B
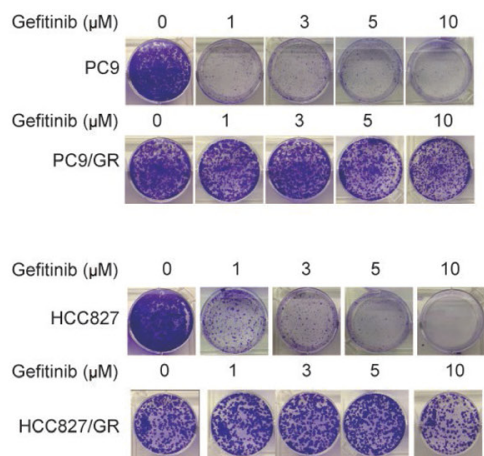

$\mathbf{E}$
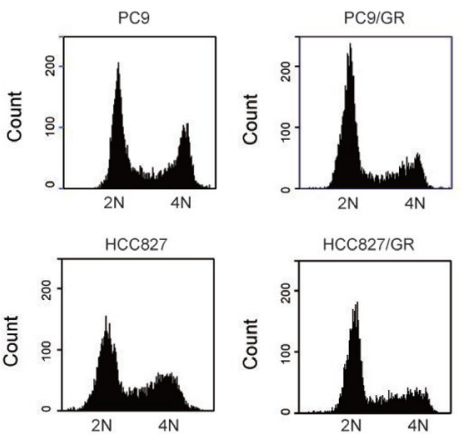

C
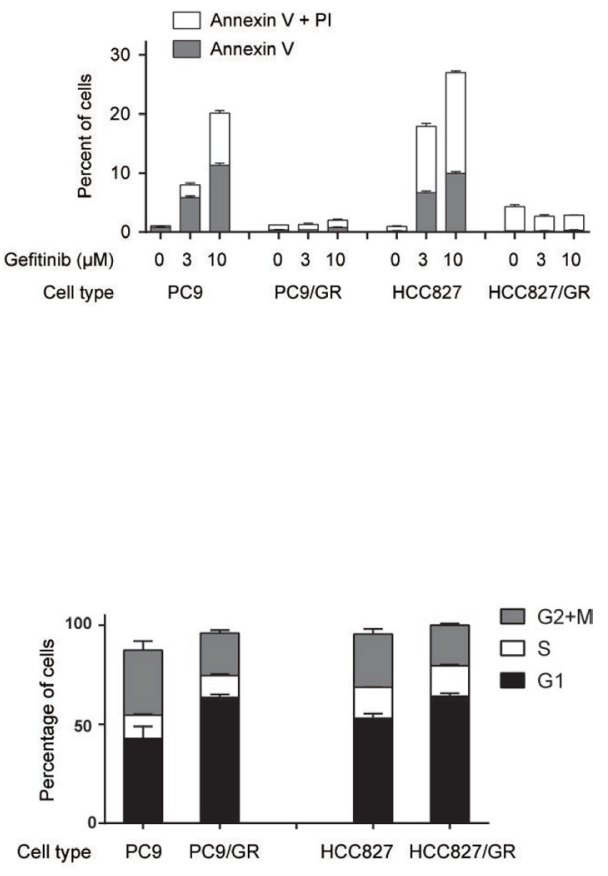

Figure 1: Characterization of gefitinib-resistant NSCLC cell lines. (A) Survival of gefitinib-sensitive (PC9 and HCC827) and gefitinib-resistant (PC9/GR and HCC827/GR) cells in response to different concentrations of gefitinib. IC $_{50}$ was given in the table (lower panel). (B) Colony formation assay of PC9, PC9/GR, HCC827, and HCC827/GR cells cultured in 0, 1, 3, 5, and 10 $\mu \mathrm{M}$ of gefitinibcontaining media. (C) Flow cytometry analysis of apoptosis in PC9, PC9/GR, HCC827, and HCC827/GR cells, treated with 0, 3, and $10 \mu \mathrm{M}$ gefitinib for 2 days. The bar graph represents percentages of cells expressing early (Annexin V) or late (PI) apoptosis markers. (D) Cell proliferation assay of PC9, PC9/GR, HCC827, and HCC827/GR cells measured at 0, 24, 48, 72, and 96 hours. G+ and G- represent the culture media with and without $3 \mu \mathrm{M}$ gefitinib, respectively. (E) PC9, PC9/GR, HCC827, and HCC827/GR cells were subjected for flow cytometry based cell cycle analysis. The histograms show the representative results generated by Accuri C6 software (left panel). The bar graphs show the percentages of cells within each cycle phase (G1, S, G2, and M) for each cell type (right panel). Analysis was performed in triplicates. Data are represented as mean (SD). 
showed that GFOLD values of most genes between these two biological replicates correlate very well in terms of differentially expressed genes (Figure 2A). In addition, hundreds of genes were either down- or up-regulated in PC9/GR cells compared with PC9 cells (Figure 2B). Genes with GFOLD values $>1$ or $<-1$ are labeled as red dots. Specifically, $6 \%$ of total detected genes (1487 genes) were up-regulated in PC9/GR cells, with a GFOLD value over 1 , and $5 \%$ of total detected genes (1112 genes) were down-regulated, with a GFOLD value less than -1 , in one replicated experiment (Figure 2C).

Next, we performed KEGG pathway enrichment analysis for the top 2000 down- or up-regulated genes in PC9/GR cells using DAVID (Supplementary Table 4). The KEGG pathways that were significantly $(P<=0.05)$ enriched for up-regulated genes included ECM-receptor interaction, O-Glycan biosynthesis, lysosome, cell adhesion molecules (CAMs) (Figure 2D). By contrast, the KEGG pathways that were significantly enriched for down-regulated genes included cell cycle, DNA replication, oxidative phosphorylation, the citrate cycle (TCA cycle), and ribosome (Figure 2E).

Since lysosome activity is closely related to autophagy, we carried out heatmap clustering analysis of autophagy related genes, and the results showed that autophagy related genes have very similar expression patterns in both replicated experiments (Figure 2F). Among 232 autophagy related genes, based on GFOLD values, we chose three most up-regulated genes: HSPB8 [31], CDKN1A [32], and ATG16L2 [33], which are known to positively regulate autophagy, and five most downregulated genes: CANX [34], EDEM1 [35], RB1CC1 [36], FOXO1 [37], and MAPK1 [38], which are known to be involved in the regulation of autophagy, for validation by RT-qPCR. We found that the $\log 2$ ratio of normalized gene expression in PC9/GR vs. those in PC9 cells from our RTqPCR results were consistent with the GFOLD values from two replicates of mRNA-Seq data (Figure 2G).

In conclusion, our mRNA-Seq analysis reveals multiple pathways involved in gefitinib-resistant NSCLC cells, and importantly, identified key genes dysregulated in the autophagy pathway enhanced in PC9/GR cells.

\section{Autophagy is enhanced in gefitinib-resistant cells and tissues}

Autophagy is enhanced in many tumor cells in response to drug treatment, which is normally associated with elevated lysosome activity [13-17]. To determine whether autophagy is also enhanced in the PC9/GR and HCC827/GR cells, we performed several experiments to detect autophagy and lysosome activity in these cells. First, we found that, LC3B-II, a marker for active autophagy, was up-regulated gradually upon the treatment with increasing amounts of gefitinib in PC9, PC9/GR, HCC827, and HCC827/GR cells (Figure 3A).
However, p62 protein level was decreased gradually at the same time (Figure 3A); Second, using transmission electron microscopy (TEM), we found that the number of autophagic vacuoles, which are indicated by the red arrows, had increased dramatically in PC9/GR and HCC827/GR cells compared with PC9 and HCC827 cells (Figure 3B). We also observed increased numbers of autophagic vacuoles in the xenograft tumors derived from the resistant cells (Supplementary Figure 2). Third, we observed an increase in the formation of lysosome foci in the resistant cells, as detected by a fluorescent dye that specifically binds to the lysosomes, indicating an elevated level of lysosome activity (Figure 3C). Finally, we conducted an immunohistochemistry assay using the xenograft tumor tissues, and found that the expression level of Ki-67 (a cellular proliferation marker) was decreased, but the autophagy marker, LC3B, was increased in the drug-resistant cells (Figure 3D, comparing lane 1 vs. lane 2 , or lane 3 vs. lane 4 ). These data reveal that autophagy and lysosomal activity were enhanced, but DNA replication was decreased, in the gefitinib-resistant cells, which is consistent with our mRNA-Seq analysis.

\section{Inhibition of autophagy suppresses gefitinib resistance}

To determine whether autophagy plays an important role in gefitinib resistance, we treated the gefitinibresistant cells with two different autophagy inhibitors, 3-Methyladenine (3-MA), and Chloroquine (CQ). 3-MA inhibits autophagy by blocking autophagosome formation via the inhibition of class III PI-3 kinase [39]. CQ is a lysosomotropic agent that neutralizes the acidic $\mathrm{pH}$ of lysosomes, thereby preventing autophagic protein degradation and causing autophagosome accumulation [40]. Treatments with $3 \mu \mathrm{M}$ gefitinib, $100 \mu \mathrm{M} 3-\mathrm{MA}$, or $10 \mu \mathrm{M}$ CQ alone could not suppress the colony formation capacity of PC9/GR and HCC827/GR cells, compared with cells treated with DMSO as the control. However, the combinatorial treatment of $3 \mu \mathrm{M}$ gefitinib and $100 \mu \mathrm{M} 3$-MA or $20 \mu \mathrm{M}$ CQ completely eradicated the colony formation capacity of PC9/GR and HCC827/ GR cells (Figure 4A and 4B). This observation indicates that the autophagy inhibitors, such as 3-MA and CQ, work synergistically with gefitinib to kill gefitinib-resistant cells.

Next, to determine whether the ATG5 protein, which is an essential component in autophagosome formation, is necessary for gefitinib resistance, we knocked down the ATG5 expression in PC9/GR and HCC827/GR cells using three different siRNAs (Figure 4C), and found that the clonogenic outgrowth of PC9/GR and HCC827/GR cells transfected with si-ATG5 \#1, \#2, or \#3 was significantly reduced compared with that of cells transfected with the control siRNA (Figure 4D). It is noteworthy that the effect caused by knocking down ATG5 was clearly weaker than 
those caused by the treatment of inhibitors (3-MA and CQ). This may be due to two reasons: 1) knocking down is the partial depletion of ATG5 gene expression, and 2) this knocking down effect by siRNA was transient, but not stable. Overall, our results suggest that the disruption of autophagy by ATG5 depletion can interfere with gefitinib resistance.

To determine the effect of autophagy inhibition on gefitinib-resistant tumor cell growth in vivo, we carried out xenograft experiments. Nude mice carrying PC9/ GR cells derived xenograft tumors were divided into four groups, which received $100 \mu \mathrm{l}$ of the following solutions by intragastrical injection twice per week: 1xPBS (as the control), $100 \mathrm{mg} / \mathrm{kg}$ gefitinib, $50 \mathrm{mg} / \mathrm{kg} \mathrm{CQ}$, and the mixture of gefitinib and CQ. Similar amounts of these drugs were used in other in-vivo studies [41, 42]. Relative tumor growth rate analysis showed that mice receiving the treatment of the mixture solution of gefitinib and CQ had the smallest relative tumor growth rate, as compared to the other three treatment groups (Figure 4E to 4F). Taken together, these observations indicate that autophagy inhibition can significantly suppress gefitinib resistant cell growth both in vitro and in vivo.

\section{ERK phosphorylation is activated in the gefitinib-resistant cells}

To study the signaling pathways involved in the gefitinib resistance, we performed WB to compare
A

RNA-Seq replicates (PC9/GR vs PC9)

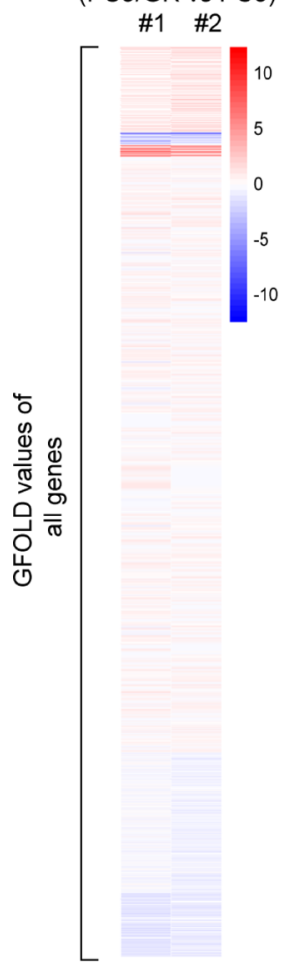

B

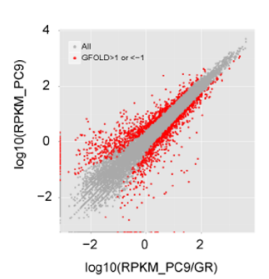

C

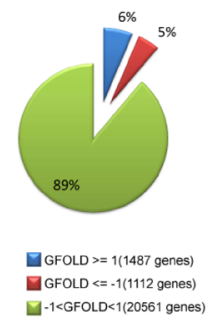

D

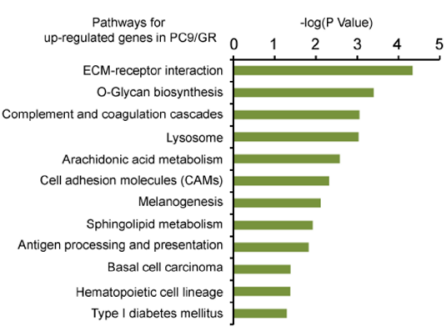

E

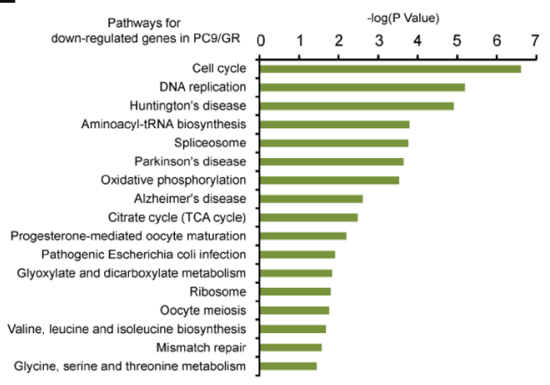

F RNA-Seq replicates (PC9/GR vs PC9)

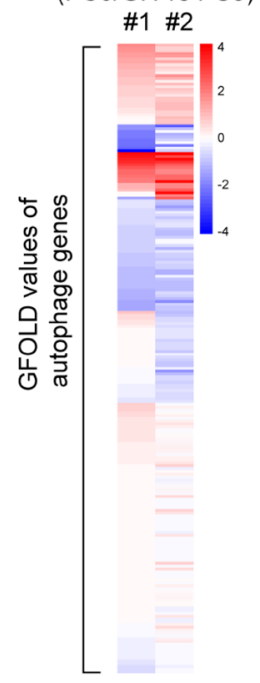

G

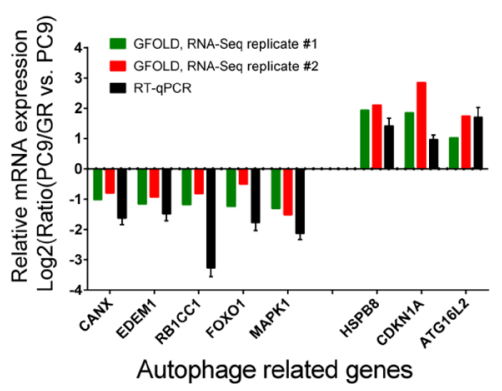

Figure 2: Transcriptome analysis of gefitinib-resistant cells. (A) Heatmap clustering of all genes based on GFOLD values from independent mRNA-Seq replicates \#1 and \#2. Red: up-regulated genes in PC9/GR cells compared to those in PC9 cells. Blue: downregulated genes in PC9/GR cells compared to those in PC9 cells. (B) Comparison of the differentially expressed genes in the PC9/GR (X axis) and PC9 cells (Y-axis), as measured by the GFOLD values. The grey dots represent all genes, the red dots represent those genes in the PC9/GR cells with GFOLD values of either $>1$ or $<-1$ compared with PC9 cells; (C) $6 \%$ of the total detected genes (1487 genes) were up-regulated (GFOLD $>=1$ ) and $5 \%$ of the total detected genes (1112genes) were down-regulated (GFOLD $<=-1)$ in the PC9/GR cells. The remaining $89 \%$ genes of the total detected genes have GFOLD values between -1 and 1 . (D-E) KEGG pathways that were significantly enriched for the up- (D) or down-regulated (E) genes in PC9/GR cells compared with the PC9 cells using DAVID analysis $(P<=0.05)$. (F) Heatmap clustering of autophagy-related genes based on GFOLD values. Blue: down-regulated genes in PC9/GR cells compared to those in PC9 cells. (G) Correlation of mRNA expression from mRNA-Seq and RT-qPCR for selected autophagy genes. Y axis represents the Log2 transformed mRNA expression levels from three experiments: mRNA-Seq replicate \#1 and \#2, and RT-qPCR. 
the activities of several signaling pathways between the sensitive cells without gefitinib treatment and the resistant cells in the presence of $3 \mu \mathrm{M}$ gefitinib treatment. We found that EGFR (on Tyr1068) phosphorylation (P-EGFR) was significantly suppressed in PC9/GR and HCC827/GR cells in the presence of gefitinib (Figure 5A).
However, ERK (on Thr202/Tyr204) and AKT (on Ser473) phosphorylation were enhanced in these cells, compared with their sensitive counterparts (Figure 5A). In addition, LC3B-II, which is associated with active autophagy, was increased in the gefitinib-resistant cells (Figure 5A). However, PC9/GR cells didn't show LC3B-II
A

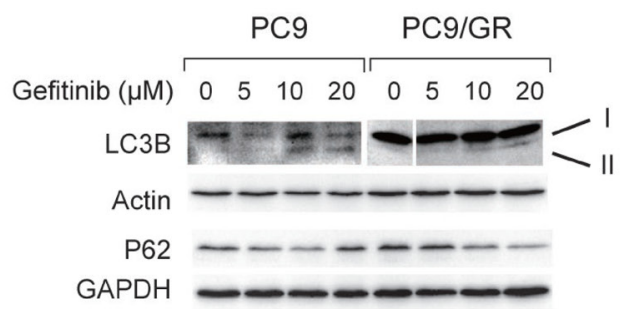

B

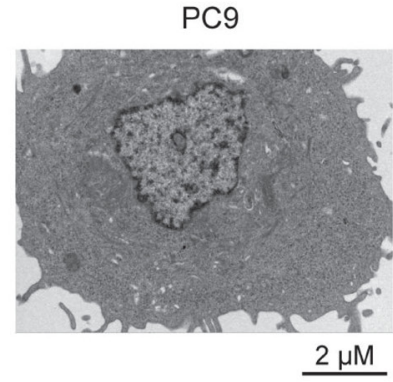

C
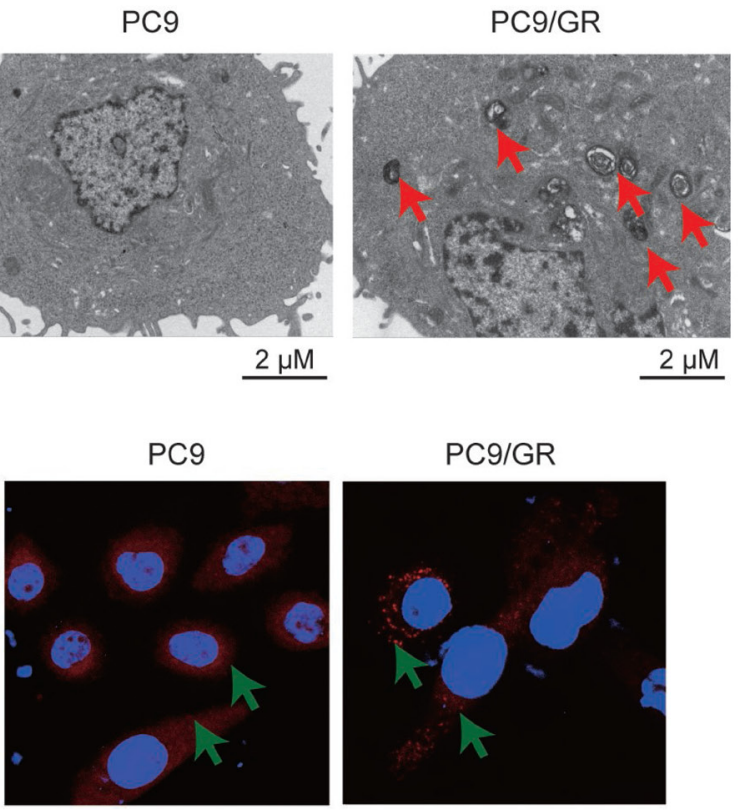

D

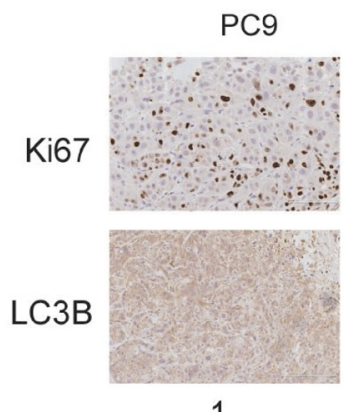

1

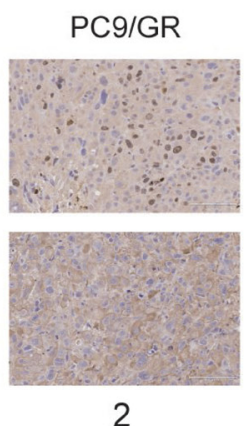

2
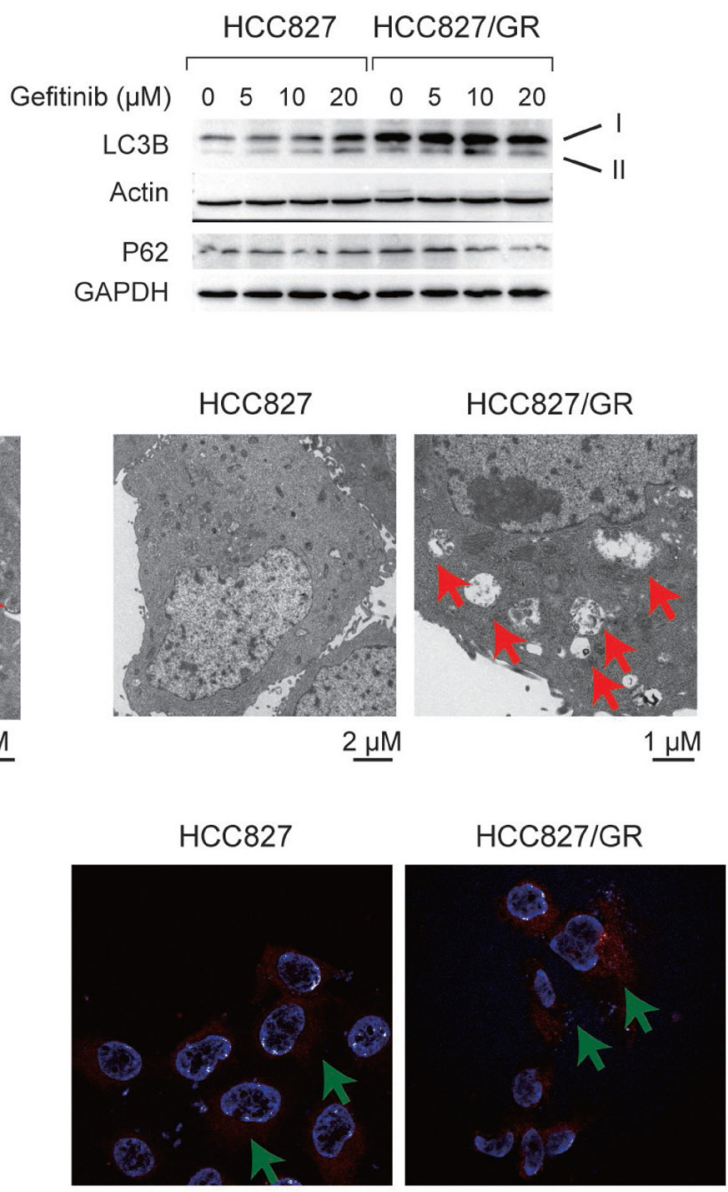

$\mathrm{HCC} 827$
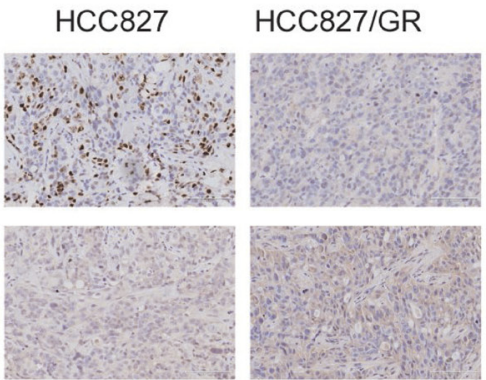

3

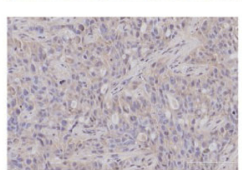

4

Figure 3: Autophagy is enhanced in the gefitinib-resistant NSCLC cells and tissues. (A) WB detection of LC3B-I, LC3B-II, and P62 proteins in PC9 and PC9/GR cells (left panel) and HCC827 and HCC827/GR cells (right panel). Actin and GAPDH served as loading controls. (B) TEM images of PC9 and PC9/GR cells (left panel) and HCC827 and HCC827/GR cells (right panel). Red arrows point to autophagic vacuoles presented in gefitinib-resistant cells (PC9/GR and HCC827/GR), which are absent in gefitinib-sensitive cells (PC9 and HCC827). (C) Confocal microscopic images of the lysosomes in the PC9 and PC9/GR cells (left panel) and HCC827 and HCC $827 / G R$ cells (right panel). Red: lysosome tracker-stained lysosome. Blue: Hoechst 33258-stained nuclei. The green arrow points to the lysosome. (D) Immunohistochemical staining of Ki-67 and LC3B proteins in xenograft tumor tissues derived from PC9 (lane 1), PC9/ GR (lane 2), HCC827 (lane 3), and HCC827/GR cells (lane 4). 
expression as strong as those in HCC827/GR cells, this may due to the smaller gefitinib concentration $(3 \mu \mathrm{M})$ used here (Figures 5A vs. 3A). Interestingly, Beclin 1 phosphorylation on Ser93 was inhibited in PC9/GR and HCC 827/GR cells, which is consistent with a previous report that EGFR phosphorylation promotes Beclin 1 phosphorylation [43] (Figure 5A). These data suggest that EGFR phosphorylation is suppressed, but ERK and AKT signaling and autophagy are up-regulated in the gefitinibresistant cells.

To examine the dynamic changes in the signaling pathways that respond to treatments with increasing gefitinib concentrations, we cultured these cells with increasing concentrations of gefitinib $(0,0.3,0.6,1.5,3,5$, 10 , and $20 \mu \mathrm{M}$ ) for 2 days, and found that ERK and AKT phosphorylation (P-ERK and P-AKT) rapidly decreased in
PC9 and HCC827 cells in the presence of $0.3 \mu \mathrm{M}$ or more gefitinib. However, P-ERK and P-AKT were stable and persisted in the PC9/GR and HCC827/GR cells (Figure 5B and 5C). Interestingly, while P-EGFR rapidly decreased in PC9, PC9/GR, and HCC827 cells under the treatment of increasing concentrations of gefitinib, P-EGFR decreased first, then increased later in HCC 827/GR cells when treating with increasing concentrations of gefitinib, indicating the differential gefitinib response of PC9/GR and HCC827/GR cells (Figure 5B and 5C).

Finally, to determine the changes in the signaling events over time, we treated these cells with $3 \mu \mathrm{M}$ gefitinib for various amounts of time $(0,0.5,1,2,5,12,24$, and 48 hours), and found that P-EGFR, P-AKT, and P-ERK were rapidly suppressed in PC9 cells at as early as 0.5 hour. However, in PC9/GR cells, P-EGFR remained at
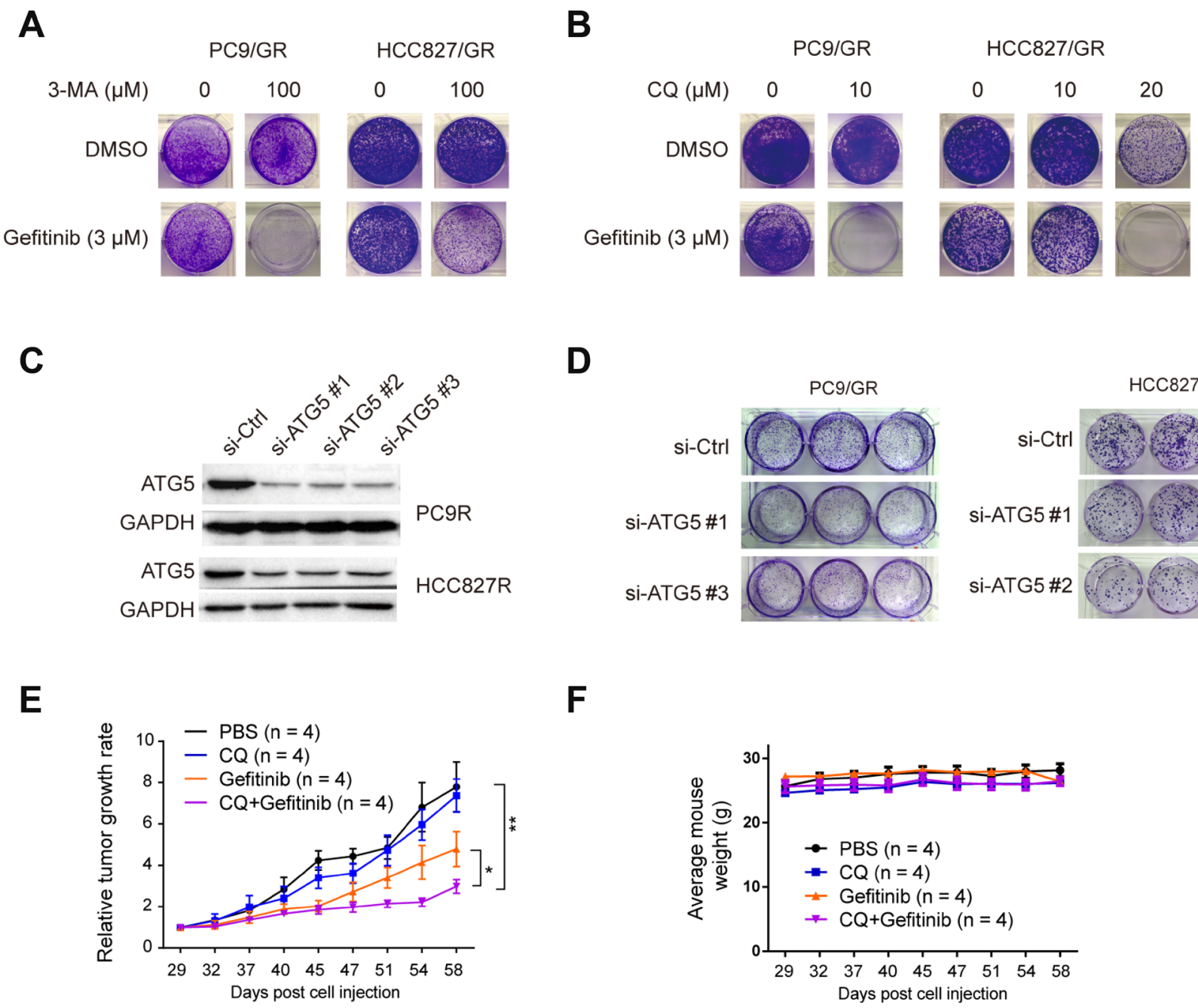

D

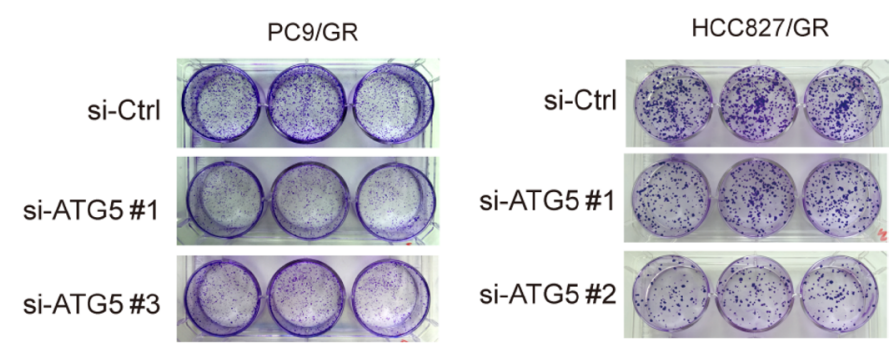

$\mathbf{F}$

Figure 4: Inhibition of autophagy suppresses gefitinib resistance. (A) PC9/GR and HCC827/GR cells were treated with either 0 or $100 \mu \mathrm{M}$ 3-MA. (B) PC9/GR and HCC827/GR cells were treated with 0, 10, or $20 \mu \mathrm{M}$ CQ for 2 days in combination with either DMSO (as the control) or $3 \mu \mathrm{M}$ gefitinib, and then continued to proliferate and form colonies for 12 days. (C) WB validation of ATG5 knockdown by three different siRNA against ATG5 (si-ATG5\#1, \#2, or \#3), compared with the control siRNA (si-Control) in PC9/GR and HCC827/ GR cells. (D) Colony formation assay of PC9/GR and HCC827/GR cells transfected with si-ATG5\#1, \#2 or \#3, compared with si-Control. (E) The relative tumor growth curves of PC9/GR derived xenograft tumors under different treatments. (F) Mice body weight curve over the same period of time as in $(\mathbf{E})$. 
a constant low level, P-AKT and P-ERK increased at 5 hours after the initiation of the treatment (Supplementary Figure 3). Together, these results suggest that, although EGFR phosphorylation was suppressed, AKT and ERK phosphorylations were increased in gefitinib-resistant cells.

\section{Inhibition of ERK phosphorylation reverses gefitinib resistance by suppressing autophagy}

To study whether ERK phosphorylation plays a key role in gefitinib resistance, we used a small molecule inhibitor of ERK1/2, TIC10, which was widely used in other studies [44, 45], and found that $3 \mu \mathrm{M}$ gefitinib treatment alone did not affect the clonogenic outgrowth of the gefitinib-resistant cells compared with those treated with DMSO. However, $20 \mu \mathrm{M}$ TIC10 alone significantly reduced the colony number of PC9R cells. Furthermore, the combination of $20 \mu \mathrm{M}$ TIC10 and $3 \mu \mathrm{M}$ gefitinib completely eradicated the colony number of the gefitinibresistant cells (Figure 6A), indicating that the ERK signaling is necessary for gefitinib resistance and ERK inhibition combined with gefitinib abrogated gefitinib resistance.
Next, to determine whether the ERK signaling is necessary for gefitinib resistance, we knocked down the ERK1 expression in PC9/GR and HCC827/GR cells using three different siRNAs against ERK1 (Figure 6B), and found that the clonogenic outgrowth of PC9/GR and HCC827/GR cells transfected with si-ERK1 \#1, or \#3 was significantly reduced compared with the cells transfected with the siRNA control (Figure 6C). This result suggests that the disruption of ERK signaling by ERK1 depletion can interfere with gefitinib resistance.

To determine whether the effect of ERK inhibition on gefitinib resistance may be due to suppressed autophagy, we performed $\mathrm{WB}$ and found that, in the presence of $3 \mu \mathrm{M}$ gefitinib, $20 \mu \mathrm{M}$ TIC10 treatment decreased the expression of LC3B-II, but increased the expression of p62 in both cells (Figure 6D, comparing lane 2 vs. lane 3 , or lane 6 vs. lane 7), indicating that autophagy was suppressed in the resistant cells as the result of ERK1/2 inhibition. In addition, there were no significant changes in ATG5 and ATG7 expressions in these cells (Figure 6D, comparing lane 2 vs. lane 3, or lane 6 vs. lane 7). These results suggest that TIC10 suppresses

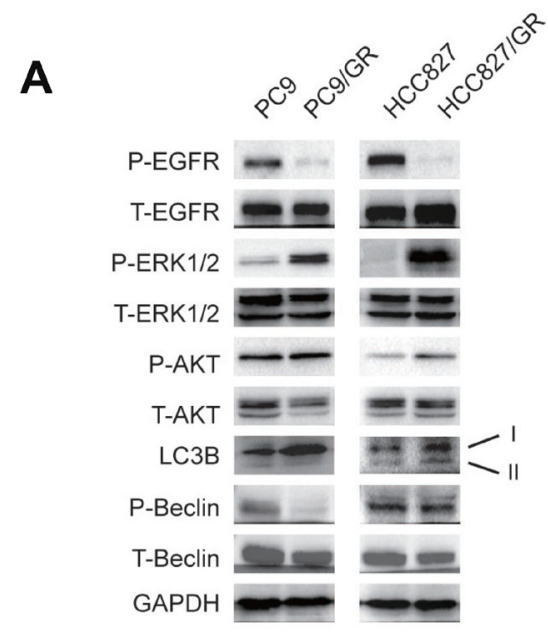

B

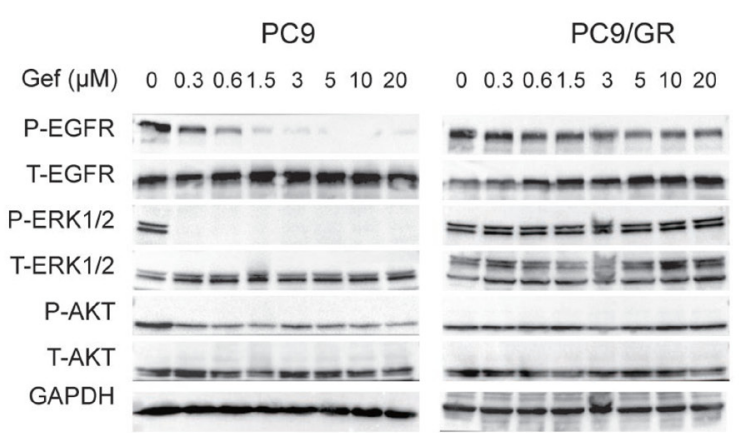

C

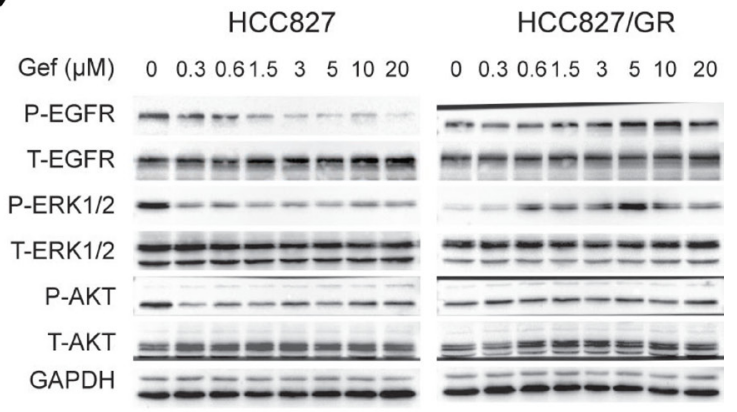

Figure 5: ERK phosphorylation is activated in gefitinib-resistant NSCLC cells. (A) WB detection of the total (T-) and phosphorylated (P-) EGFR, ERK1/2, AKT, Beclin 1, and LC3B expression levels in PC9, PC9/GR, HCC827, and HCC827/GR cells. (B-C) WB detection of the total and phosphorylated EGFR, ERK1/2, and AKT levels in the PC9 and PC9/GR cells (B) and HCC827 and HCC827/GR cells (C) cultured in media containing $0,0.3,0.6,1.5,3,5,10$, and $20 \mu \mathrm{M}$ gefitinib for two days. 
autophagy by inhibiting LC3B-II formation in gefitinibresistant cells.

We further confirmed the above findings by using another ERK inhibitor, SCH772984. PC9/GR and HCC827/GR cells treated with both gefitinib and SCH772984 had significantly the fewer number of cell colonies, as compared to these cells treated with DMSO, gefitinib, or SCH772984 alone (Supplementary Figure 4A). In addition, WB analysis indicated that LC3B was down-regulated, while P62 was up-regulated in these cells treated with SCH772984, as compared to other treatments (Supplementary Figure 4B). Therefore, we concluded that ERK inhibition by SCH772984 can also suppress autophagy in these gefitinib-resistant cells.
To determine the effect of ERK1 inhibition on gefitinib-resistant tumor cell growth in vivo, we carried out xenograft tumor experiments. Nude mice carrying PC9/ GR cells derived xenograft tumors were divided into four groups, which received $100 \mu$ l of the following treatments by intragastrical injection: 1xPBS (as the control), $100 \mathrm{mg} / \mathrm{kg}$ gefitinib, $25 \mathrm{mg} / \mathrm{kg}$ TIC10, and the combination of gefitinib and TIC10. Similar amounts of these drugs were used in other in-vivo studies [44, 45]. Comparisons of tumor growth curve and tumor weight showed that the mice receiving the combined treatment of gefitinib and TIC10 had the significantly slower tumor growth rate and the significantly smaller tumor weight than those receiving the control treatment, while the average mice weight is

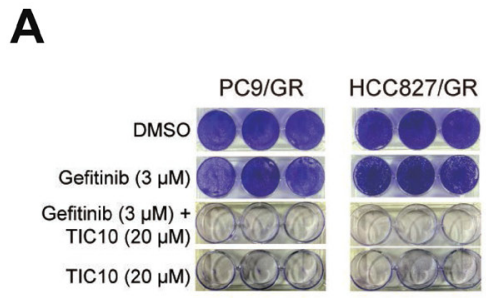

D

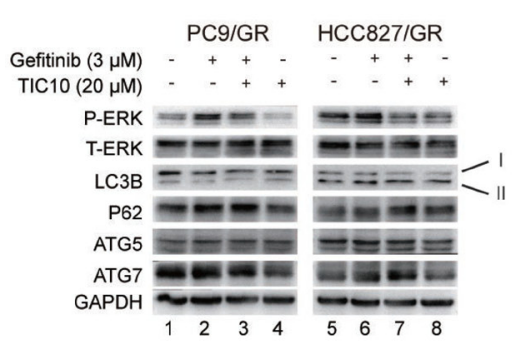

G

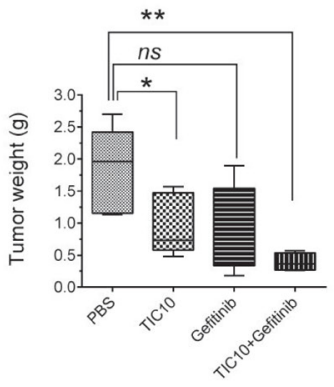

B

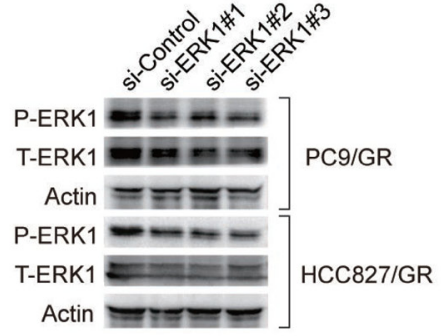

E

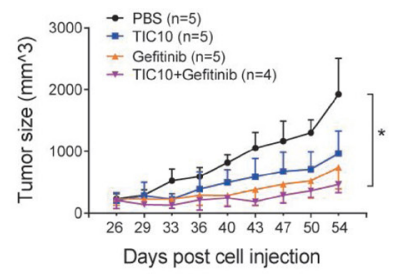

H

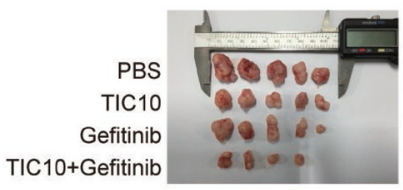

C

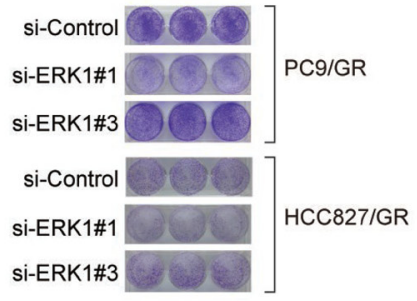

F

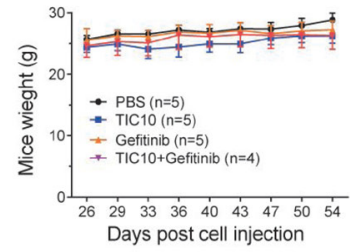

I

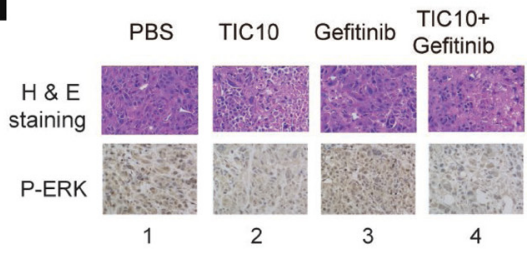

Figure 6: Inhibition of ERK phosphorylation reverses gefitinib resistance by suppressing autophagy. (A) PC9/GR and HCC 827/GR cells were cultured in media containing either DMSO (as the control), $20 \mu \mathrm{M}$ TIC10 (ERK1/2 inhibitor), $3 \mu \mathrm{M}$ gefitinib, or the combination of both TIC10 and gefitinib, for 12 days, followed by the colony formation assay. (B) WB validation of ERK1 knockdown by three different siRNAs against ERK1 (si-ERK1\#1, \#2, and \#3) compared with the control siRNA (si-Control) in PC9/GR and HCC827/ GR cells. (C) Colony formation assay of PC9/GR and HCC827/GR cells transfected with si-ERK1 \#1, \#2, or \#3, compared with siControl. (D) WB detection of the total and phosphorylated ERK1/2, LC3B, p62, ATG5, ATG7 levels in the PC9/GR and HCC827/GR cells cultured in the four treatment conditions described as above. (E-F) Growth curves of PC9/GR cells derived xenograft tumors (E) and mice body weights (F) in four treatment groups: PBS (as the control), gefitinib only, TIC10 only, and the combination of gefitinib and TIC10. (G) Images of isolated xenograft tumors from four treatment groups. (H) Comparison of average xenograft tumor weights from four treatment groups. (I) H\&E staining and immunohistochemical images of phosphorylated ERK expression of xenograft tissues from four treatment groups. 
comparable among all four treatment groups (Figures 6E to $6 \mathrm{H})$. Interestingly, TIC10 treatment alone also reduced the tumor size due to its antitumor effect, but its inhibitory effect was not strong as the combined treatment of gefitinib and TIC10. Subsequent immunochemical staining images showed that the ERK phosphorylation level was reduced in xenograft tumor tissues receiving TIC10 treatment (Figure 6I, lanes 2 and 4), compared to those without TIC10 treatment (Figure 6I, lanes 1 and 3 ).

Therefore, we concluded that pharmacological inhibition of the ERK signaling can significantly reduce gefitinib-resistant tumor cell growth both in vitro and in vivo by suppressing autophagy.

\section{DISCUSSION}

In this study, we generated two novel gefitinibresistant NSCLC cell lines and compared their $\mathrm{IC}_{50}$ of gefitinib, anti-apoptosis abilities, and growth rates with gefitinib-sensitive NSCLC cells. In addition, we found that multiple pathways are dysregulated in gefitinibresistant cells. Importantly, autophagy was enhanced in the gefitinib-resistant cells, and the inhibition of autophagy suppressed the gefitinib resistance. We also found that phosphorylations of ERK and AKT are activated in resistant cells. Inhibition of ERK phosphorylation greatly suppressed gefitinib resistance both in vitro and in vivo. Based on these observations, we propose a model for the mechanism of gefitinib resistance (Supplementary Figure 5). In this model, ERK phosphorylation promotes autophagy by stimulating LC3B-II formation, and p62 degradation. This leads to gefitinib resistance in NSCLC cells.

Multiple signaling pathways have been found to be important for drug resistance. For example, hyperactive ERK and persistent mTOR signaling promote vemurafenib resistance in papillary thyroid cancer cells [46]; mTOR was associated with drug resistance in lung adenocarcinoma after radiation combined with TKI, and mTOR inhibition reverses drug resistance in lung adenocarcinoma after combined radiation and TKI therapy [47]; dual inhibition of AKT signaling/FLT3-ITD by the well-established orally available AKT inhibitor, A674563, overcomes FLT3 ligandinduced drug resistance in FLT3-ITD positive AML [48].

Our mRNA-Seq-based transcriptome analysis reveals several significantly up- or down-regulated pathways that are associated with gefitinib resistance. In addition to enhanced lysosome activity, other cellular pathways, such as ECM-receptor interaction, cell adhesion molecules (CAMs), and the O-glycan biosynthesis pathways, may also be involved in regulating gefitinib resistance and autophagy. For example, the ECM protects small-cell lung cancer cells from DNA damage-induced cell cycle arrest and apoptosis through betal integrindependent activation of PI3 kinase [49]. Integrin-mediated adhesion regulates ERK nuclear translocation and phosphorylation of Elk-1 [50]. We are currently studying how these pathways affect gefitinib resistance, which may reveal new information on the molecular mechanism of acquired gefitinib resistance.

In our study, we found that inhibition of autophagy by CQ or inhibition of ERK by TIC10 can suppress the gefitinib resistance in vivo. In fact, many clinical trials are currently underway to investigate the effect of autophagy inhibitors (CQ and hydroxychloroquine (HCQ)) or the ERK inhibitor (TIC10, ONC201 (other name)) in treating advanced solid tumors. For example, along with other therapies, CQ and HCQ are being tested in clinical trials to treat cancer [13]. The NCT02378532 and NCT02333890 clinical trials to treat glioblastoma and breast cancer are currently evaluating the effect of CQ on radioresistant cancers. In addition, clinical studies of oral ONC201 are underway in patients with relapsed non-hodgkin's lymphoma, adult recurrent glioblastoma, and relapsed acute leukemia, etc. Even though our data reveal the importance of the ERK signaling in gefitinibresistant NSCLC cells, there are still many unanswered questions left: how the ERK signaling is enhanced during the gefitinib resistance, and how it promotes autophagy. Further studies are needed to address these questions.

Overall, our study uncovers new cellular pathways involved in gefitinib resistance, and reveals that the ERK signaling plays an important role in promoting autophagyinduced gefitinib resistance. Our work also suggests that inhibitors targeting the ERK signaling may be effective in preventing acquired gefitinib resistance in NSCLC patients.

\section{MATERIALS AND METHODS}

\section{Ethics}

All animal experiments were performed using male $\mathrm{BALB} / \mathrm{C}$ nude mice (4-5 weeks old). The mice were purchased from the SLAC Laboratory Animal Center (Shanghai, China) and cared for in accordance with the Guide for the Care and Use of Laboratory Animals from the National Institutes of Health. All animal experimental protocols performed in this study were approved by the Institutional Animal Care and Use Committee at Tongji University (IACUC No. 1201).

\section{Cell culture}

Four human NSCLC cell lines were used in this study, including two gefitinib-sensitive cell lines, PC9 and HCC827, and two gefitinib-resistant cell lines, PC9/GR and HCC827/GR. PC9 and PC9/GR cells were grown in DMEM medium (Hyclone, GE Healthcare Life Sciences, Utah, USA). HCC827 and HCC827/GR cells were grown in RPMI-1640 (Hyclone). All medium contained 10\% FBS (Gibco) supplemented with penicillin $(100 \mathrm{U} / \mathrm{ml})$ and streptomycin (100 mg/ml) (Life Technologies). In addition, gefitinib was added to the medium of PC9/GR 
and HCC827/GR cells at a final concentration of $3 \mu \mathrm{M}$. Cells were incubated at $37^{\circ} \mathrm{C}$ in a humidified atmosphere with $5 \% \mathrm{CO}_{2}$.

\section{Colony formation assay}

Colony formation assays were performed as previously described [51].

\section{Cell proliferation assay}

Colony proliferation assays were performed as previously described [51].

\section{siRNA transfection}

The ATG5 and ERK1 siRNAs were synthesized by GenePharma Inc. (Shanghai, China). The transfections were performed with Lipofectamine 2000 (11668019, Invitrogen, CA, USA) according to the manufacturer's protocol. The total RNA or cell lysates were prepared 48 $\mathrm{h}$ after transfection and were used for Western blotting analyses, respectively.

The sequences for the siRNAs against ATG5 are as follows: \#1: sense (5'-3') GACGUUGGUAA CUGACAAATT and antisense (5'-3') UUUGUCAGUUA CCAACGUCTT; \#2: sense (5'-3') GUCCAUCUAAGG AUGCAAUTT and antisense (5'-3') AUUGCAUCCUUA GAUGGACTT; \#3: sense (5'-3') GACCUUUCAUUCAGA AGCUTT and antisense (5'-3') AGCUUCUGAAUGAAAG GUCTT.

The sequences for the siRNAs against ERK1 are as follows: \#1: sense (5'-3') CCUUCGAACAUC AGACCUATT and antisense (5'-3') UAGGUCUGA UGUUCGAAGGTT; \#2: sense (5'-3') GAGAUGUCUA CAUUGUGCATT and antisense (5'-3') UGCACAA UGUAGACAUCUCTT; \#3: sense (5'-3') CUGCGACCU UAAGAUUUGUTT and antisense (5'-3') ACAAAUC UUAAGGUCGCAGTT.

\section{Western blotting (WB)}

Western blotting was performed as previously described [51]. The antibodies and catalogue numbers are listed (Supplementary Table 1).

\section{RNA isolation and real-time RT-PCR}

Total RNA extraction from cells and real-time RT-PCR were performed as previously described [51]. The PCR primer names and sequences are listed (Supplementary Table 2).

\section{$\mathrm{IC}_{50}$ determination}

Totals of 2,000-4,000 PC9 and HCC827 cells or 3,000 PC9/GR and HCC827/GR cells were seeded in 96- well plates, incubated with the indicated concentrations of gefitinib for three or four days, and assessed for the cell survival with the MTS reagent (Promega G3580). Survival data were analyzed, and $\mathrm{IC}_{50}$ was determined using the Prism GraphPad software (version 6.01).

\section{mRNA-seq library preparation}

The total RNA was extracted from the PC9 and PC9/ GR cells using RNAprep Pure (Tiangen, DP430, Shanghai, China), and the mRNAs were purified using the Dynabeads mRNA purification kit (Invitrogen, 61006). The cDNAs were synthesized and used to construct a library with the NEBNext Ultra RNA Library Prep Kit (NEB, E7530). The libraries were sequenced on the Illumina HiSeq2000 platform via a $1 \times 50 \mathrm{bp}$ single-end sequencing at BGI Tech Solutions Co., Ltd. (Shenzhen, China).

\section{RNA-seq data analysis}

The RNA-Seq reads were aligned to the hg19 genome assembly using TopHat (version 1.1.4) with the default parameters [52]. The expression index was generated using GFOLD V1.1.3 job count [30] from the bam files from TopHat. The differentially expressed genes were ranked using GFOLD V1.1.3 job diff [30]. The final output file contains all genes with a GFOLD value, which could be considered as the reliable log2fold change between the control (PC9) and treatment (PC9/GR) conditions. Pathway enrichment analyses were performed by DAVID (http://david.abcc.ncifcrf.gov) [53]. The heatmap clustering analysis was done using K-means clustering method in $\mathrm{R}$ (version 3.2.3).

All sequencing data were deposited in the NCBI Gene Expression Omnibus (GEO) (http://www.ncbi.nlm. nih.gov/geo/) under accession number GSE74253.

\section{Small molecule inhibitors}

The following small molecule inhibitors were used in this study: gefitinib, an EGFR inhibitor (IRESSA, AstraZeneca); 3-Methyladenine (3-MA) (Selleck, S2767); Chloroquine Phosphate (CQ) (Selleck, S4157); and TIC10, an ERK and AKT inhibitor (MCE, HY-15615A).

\section{Transmission electron microscopy (TEM)}

A $1 \mathrm{~cm}^{3}$ block of tissue or $1 \times 10^{6}$ cells were fixed in an electron microscope fixing solution (Wuhan Google Biotechnology, \#G1102), and sent for TEM imaging analysis using a Tecnai G2 200kV Transmission Electron Microscope (FEI, USA), with photos taken at various magnifications.

\section{Fluorescent confocal microscopy}

The cells cultured in 12-well plates were fixed in 4\% Paraformaldehyde, washed with PBS, and stained with $500 \mu \mathrm{l}$ 
of Lyso-tracker Red (Beyotime Biotechnology, \#C1046) and Hoechst 33258 (Beyotime Biotechnology, \#C1011). An anti-fluorescent quenching liquid (Beyotime Biotechnology \#P0126) was added to the solution. The cells were observed using a $90 \mathrm{i}$ confocal microscope (Nikon, Japan).

\section{Immunohistochemistry}

The immunohistochemistry experiments were performed by Wuhan google technology Co. LTD. (http:// servicebio.cn/, Wuhan, China). Briefly, the formalinembedded tumor tissue samples were sliced and subjected to immunohistochemistry using the following primary antibodies: Ki67 (ab15580, Abcam, USA), LC3B (PM036, MBL, USA). The primary antibodies were detected with EnVision $^{\mathrm{TM}}$ Detection Systems Peroxidase/DAB, Rabbit/ Mouse (K5007, Dako, USA).

\section{Apoptosis assay}

Apoptosis assays were performed as previously described [54].

\section{Xenograft assay}

Male nude mice were purchased from Shanghai SLAC Laboratory Animal Center. A total of $2 \times 10^{6}$ PC9/GR cells suspended in $100 \mu \mathrm{L} 1 \times$ PBS was injected subcutaneously into the right axillary part of 5-week old mice. When the tumor size reached $100 \mathrm{~mm}^{3}, 20$ mice were randomly divided into four groups. Mice in different groups were intragastrically injected with $100 \mu \mathrm{l}$ of the following solution containing: 1xPBS, CQ (50 mg/kg), gefitinib (100 mg/kg), CQ followed by gefitinib, respectively. Relative tumor growth rate was calculated as the ratio of the tumor size at a given time point vs. the tumor size at the time point of drug injection the first time.

For TIC10 in vivo assay, PC9/GR cells derived xenograft tumors were allowed to grow to around $100 \mathrm{~mm}^{3}$, then mice were divided into four groups. Mice in different groups were intragastrically injected with $100 \mu \mathrm{l}$ of the following solution containing: 1xPBS, TIC10 (25 mg/kg), gefitinib (100 mg/kg), the mixture of TIC10 and gefitinib, respectively.

Treatment was done twice per week. Tumor size was measured every week using the digital caliper, and its volume $(\mathrm{v})$ was calculated based on this formula: $\mathrm{v}=$ $0.5^{*} \mathrm{a}{ }^{*} \mathrm{~b} 2$, with $\mathrm{a}=$ long diameter, $\mathrm{b}=$ short diameter. After eight measurements, tumor tissues were isolated, photographed, and weighted. All procedures performed in this study are approved by the Institutional Animal Care and Use Committee at Tongji University.

\section{Statistical analysis}

Student's $T$ test was used to determine the significance of the differences between two groups.
$P<0.05$ is considered to be significant. ${ }^{*} P<0.05$, ${ }^{* *} P<0.01,{ }^{* * *} P<0.001,{ }^{* * * *} P<0.0001$.

\section{Author contributions}

MF.Q., Y.T., W.L., D.L., T.Z., YX.Y., QW. L., Y.Y., ZX. Z., TH.H., L.T., ZH.L., and YH.F. performed the experiments. D.L. and SJ.C. performed the bioinformatics analysis. B.S., F.L., K.F., P.Z., F.Z., and L.Z. analyzed and interpreted the data. F.Z. and L.Z. conceived the project, F.Z. designed the experiments, and wrote the paper with contributions from all authors.

\section{ACKNOWLEDGMENTS AND FUNDING}

We thank the Departments of Respiratory and Nuclear and Radiation of Shanghai Pulmonary Hospital for providing assistance with the IHC automatic scanning and confocal microscopy. We thank our former laboratory colleagues for providing their assistance with the experiments. This work was supported by grants from Shanghai Pulmonary Hospital, Project 985 of Tongji University (No. 129212), NSFC (81772465, 81200034, 81470244), Shanghai Science and Technology Committee (13ZR1434500, 134119a3400), Shanghai Rising-Star Program (14QA1403200), and Shanghai Medical New Excellent Youth (XYQ2013115). This project was also supported in part by grants from NIH 1R01 GM106037 and NSF MCB-1330557 (to F.L.). F. L. is a Pew Scholar in the Biomedical Sciences and is supported by The Pew Charitable Trusts.

\section{CONFLICTS OF INTEREST}

The authors declare no competing financial interests.

\section{REFERENCES}

1. Lynch TJ, Bell DW, Sordella R, Gurubhagavatula S, Okimoto RA, Brannigan BW, Harris PL, Haserlat SM, Supko JG, Haluska FG, Louis DN, Christiani DC, Settleman J, Haber DA. Activating mutations in the epidermal growth factor receptor underlying responsiveness of non-smallcell lung cancer to gefitinib. The New England journal of medicine. 2004; 350:2129-2139.

2. Zhou C, Wu YL, Chen G, Feng J, Liu XQ, Wang C, Zhang S, Wang J, Zhou S, Ren S, Lu S, Zhang L, Hu C, et al. Erlotinib versus chemotherapy as first-line treatment for patients with advanced EGFR mutation-positive nonsmall-cell lung cancer (OPTIMAL, CTONG-0802): a multicentre, open-label, randomised, phase 3 study. The Lancet Oncology. 2011; 12:735-742.

3. Paez JG, Janne PA, Lee JC, Tracy S, Greulich H, Gabriel S, Herman P, Kaye FJ, Lindeman N, Boggon TJ, Naoki K, 
Sasaki H, Fujii Y, et al. EGFR mutations in lung cancer: correlation with clinical response to gefitinib therapy. Science. 2004; 304:1497-1500.

4. Mok TS, Wu YL, Thongprasert S, Yang CH, Chu DT, Saijo N, Sunpaweravong P, Han B, Margono B, Ichinose Y, Nishiwaki Y, Ohe Y, Yang JJ, et al. Gefitinib or carboplatinpaclitaxel in pulmonary adenocarcinoma. The New England journal of medicine. 2009; 361:947-957.

5. Sordella R, Bell DW, Haber DA, Settleman J. Gefitinibsensitizing EGFR mutations in lung cancer activate antiapoptotic pathways. Science. 2004; 305:1163-1167.

6. Pao W, Miller VA, Politi KA, Riely GJ, Somwar R, Zakowski MF, Kris MG, Varmus H. Acquired resistance of lung adenocarcinomas to gefitinib or erlotinib is associated with a second mutation in the EGFR kinase domain. PLoS medicine. 2005; 2:e73.

7. Engelman JA, Zejnullahu K, Mitsudomi T, Song Y, Hyland C, Park JO, Lindeman N, Gale CM, Zhao X, Christensen J, Kosaka T, Holmes AJ, Rogers AM, et al. MET amplification leads to gefitinib resistance in lung cancer by activating ERBB3 signaling. Science. 2007; 316:1039-1043.

8. Huang S, Holzel M, Knijnenburg T, Schlicker A, Roepman P, McDermott U, Garnett M, Grernrum W, Sun C, Prahallad A, Groenendijk FH, Mittempergher L, Nijkamp W, et al. MED12 controls the response to multiple cancer drugs through regulation of TGF-beta receptor signaling. Cell. 2012; 151:937-950.

9. Bivona TG, Hieronymus H, Parker J, Chang K, Taron M, Rosell R, Moonsamy P, Dahlman K, Miller VA, Costa C, Hannon G, Sawyers CL. FAS and NF-kappaB signalling modulate dependence of lung cancers on mutant EGFR. Nature. 2011; 471:523-526.

10. Cortot AB, Repellin CE, Shimamura T, Capelletti M, Zejnullahu K, Ercan D, Christensen JG, Wong KK, Gray NS, Janne PA. Resistance to irreversible EGF receptor tyrosine kinase inhibitors through a multistep mechanism involving the IGF1R pathway. Cancer research. 2013; 73:834-843.

11. Sequist LV, Waltman BA, Dias-Santagata D, Digumarthy S, Turke AB, Fidias P, Bergethon K, Shaw AT, Gettinger S, Cosper AK, Akhavanfard S, Heist RS, Temel J, et al. Genotypic and histological evolution of lung cancers acquiring resistance to EGFR inhibitors. Science translational medicine. 2011; 3:75ra26.

12. Sharma SV, Lee DY, Li B, Quinlan MP, Takahashi F, Maheswaran S, McDermott U, Azizian N, Zou L, Fischbach MA, Wong KK, Brandstetter K, Wittner B, et al. A chromatin-mediated reversible drug-tolerant state in cancer cell subpopulations. Cell. 2010; 141:69-80.

13. Yang ZJ, Chee CE, Huang S, Sinicrope FA. The role of autophagy in cancer: therapeutic implications. Molecular cancer therapeutics. 2011; 10:1533-1541.

14. Li X, Fan Z. The epidermal growth factor receptor antibody cetuximab induces autophagy in cancer cells by downregulating HIF-1alpha and Bcl-2 and activating the beclin $1 / \mathrm{hVps} 34$ complex. Cancer research. 2010; 70:5942-5952.

15. Paglin S, Hollister T, Delohery T, Hackett N, McMahill M, Sphicas E, Domingo D, Yahalom J. A novel response of cancer cells to radiation involves autophagy and formation of acidic vesicles. Cancer research. 2001; 61:439-444.

16. Ertmer A, Huber V, Gilch S, Yoshimori T, Erfle V, Duyster J, Elsasser HP, Schatzl HM. The anticancer drug imatinib induces cellular autophagy. Leukemia. 2007; 21:936-942.

17. Liu YL, Yang PM, Shun CT, Wu MS, Weng JR, Chen CC. Autophagy potentiates the anti-cancer effects of the histone deacetylase inhibitors in hepatocellular carcinoma. Autophagy. 2010; 6:1057-1065.

18. Furuya N, Yu J, Byfield M, Pattingre S, Levine B. The evolutionarily conserved domain of Beclin 1 is required for Vps34 binding, autophagy and tumor suppressor function. Autophagy. 2005; 1:46-52.

19. Kihara A, Kabeya Y, Ohsumi Y, Yoshimori T. Beclinphosphatidylinositol 3-kinase complex functions at the trans-Golgi network. EMBO reports. 2001; 2:330-335.

20. Satoo K, Noda NN, Kumeta H, Fujioka Y, Mizushima $\mathrm{N}$, Ohsumi Y, Inagaki F. The structure of Atg4B-LC3 complex reveals the mechanism of LC3 processing and delipidation during autophagy. The EMBO journal. 2009; 28:1341-1350.

21. Pankiv S, Clausen TH, Lamark T, Brech A, Bruun JA, Outzen H, Overvatn A, Bjorkoy G, Johansen T. p62/ SQSTM1 binds directly to Atg8/LC3 to facilitate degradation of ubiquitinated protein aggregates by autophagy. The Journal of biological chemistry. 2007; 282:24131-24145.

22. Mathew R, Karp CM, Beaudoin B, Vuong N, Chen G, Chen HY, Bray K, Reddy A, Bhanot G, Gelinas C, Dipaola RS, Karantza-Wadsworth V, White E. Autophagy suppresses tumorigenesis through elimination of p62. Cell. 2009; 137:1062-1075.

23. Qu X, Yu J, Bhagat G, Furuya N, Hibshoosh H, Troxel A, Rosen J, Eskelinen EL, Mizushima N, Ohsumi Y, Cattoretti $\mathrm{G}$, Levine B. Promotion of tumorigenesis by heterozygous disruption of the beclin 1 autophagy gene. The Journal of clinical investigation. 2003; 112:1809-1820.

24. Kanzawa T, Zhang L, Xiao L, Germano IM, Kondo Y, Kondo S. Arsenic trioxide induces autophagic cell death in malignant glioma cells by upregulation of mitochondrial cell death protein BNIP3. Oncogene. 2005; 24:980-991.

25. Guo JY, Chen HY, Mathew R, Fan J, Strohecker AM, KarsliUzunbas G, Kamphorst JJ, Chen G, Lemons JM, Karantza V, Coller HA, Dipaola RS, Gelinas C, et al. Activated Ras requires autophagy to maintain oxidative metabolism and tumorigenesis. Genes \& development. 2011; 25:460-470.

26. Kolch W. Coordinating ERK/MAPK signalling through scaffolds and inhibitors. Nature reviews Molecular cell biology. 2005; 6:827-837. 
27. Hatzivassiliou G, Liu B, O'Brien C, Spoerke JM, Hoeflich KP, Haverty PM, Soriano R, Forrest WF, Heldens S, Chen H, Toy K, Ha C, Zhou W, et al. ERK inhibition overcomes acquired resistance to MEK inhibitors. Molecular cancer therapeutics. 2012; 11:1143-1154.

28. Ercan D, Xu C, Yanagita M, Monast CS, Pratilas CA, Montero J, Butaney M, Shimamura T, Sholl L, Ivanova EV, Tadi M, Rogers A, Repellin C, et al. Reactivation of ERK signaling causes resistance to EGFR kinase inhibitors. Cancer discovery. 2012; 2:934-947.

29. Abrams SL, Steelman LS, Shelton JG, Wong EW, Chappell WH, Basecke J, Stivala F, Donia M, Nicoletti F, Libra M, Martelli AM, McCubrey JA. The Raf/MEK/ERK pathway can govern drug resistance, apoptosis and sensitivity to targeted therapy. Cell cycle. 2010; 9:1781-1791.

30. Feng J, Meyer CA, Wang Q, Liu JS, Shirley Liu X, Zhang Y. GFOLD: a generalized fold change for ranking differentially expressed genes from RNA-seq data. Bioinformatics. 2012; 28:2782-2788.

31. Crippa V, Sau D, Rusmini P, Boncoraglio A, Onesto E, Bolzoni E, Galbiati M, Fontana E, Marino M, Carra S, Bendotti C, De Biasi S, Poletti A. The small heat shock protein B8 (HspB8) promotes autophagic removal of misfolded proteins involved in amyotrophic lateral sclerosis (ALS). Human molecular genetics. 2010; 19:3440-3456.

32. Orlotti NI, Cimino-Reale G, Borghini E, Pennati M, Sissi C, Perrone F, Palumbo M, Daidone MG, Folini M, Zaffaroni N. Autophagy acts as a safeguard mechanism against G-quadruplex ligand-mediated DNA damage. Autophagy. 2012; 8:1185-1196.

33. Ishibashi K, Fujita N, Kanno E, Omori H, Yoshimori T, Itoh T, Fukuda M. Atg16L2, a novel isoform of mammalian Atg16L that is not essential for canonical autophagy despite forming an Atg12-5-16L2 complex. Autophagy. 2011; 7:1500-1513.

34. Melland-Smith M, Ermini L, Chauvin S, Craig-Barnes H, Tagliaferro A, Todros T, Post M, Caniggia I. Disruption of sphingolipid metabolism augments ceramide-induced autophagy in preeclampsia. Autophagy. 2015; 11:653-669.

35. Cali T, Galli C, Olivari S, Molinari M. Segregation and rapid turnover of EDEM1 by an autophagy-like mechanism modulates standard ERAD and folding activities. Biochemical and biophysical research communications. 2008; 371:405-410.

36. Morselli E, Shen S, Ruckenstuhl C, Bauer MA, Marino G, Galluzzi L, Criollo A, Michaud M, Maiuri MC, Chano T, Madeo F, Kroemer G. p53 inhibits autophagy by interacting with the human ortholog of yeast Atg17, RB1CC1/FIP200. Cell cycle. 2011; 10:2763-2769.

37. Zhao Y, Yang J, Liao W, Liu X, Zhang H, Wang S, Wang D, Feng J, Yu L, Zhu WG. Cytosolic FoxO1 is essential for the induction of autophagy and tumour suppressor activity. Nature cell biology. 2010; 12:665-675.
38. Bravo-San Pedro JM, Gomez-Sanchez R, Niso-Santano M, Pizarro-Estrella E, Aiastui-Pujana A, Gorostidi A, Climent V, Lopez de Maturana R, Sanchez-Pernaute R, Lopez de Munain A, Fuentes JM, Gonzalez-Polo RA. The MAPK1/3 pathway is essential for the deregulation of autophagy observed in G2019S LRRK2 mutant fibroblasts. Autophagy. 2012; 8:1537-1539.

39. Wu YT, Tan HL, Shui G, Bauvy C, Huang Q, Wenk MR, Ong CN, Codogno P, Shen HM. Dual role of 3-methyladenine in modulation of autophagy via different temporal patterns of inhibition on class I and III phosphoinositide 3-kinase. The Journal of biological chemistry. 2010; 285:10850-10861.

40. Shintani T, Klionsky DJ. Autophagy in health and disease: a double-edged sword. Science. 2004; 306:990-995.

41. Guix M, Faber AC, Wang SE, Olivares MG, Song Y, Qu S, Rinehart C, Seidel B, Yee D, Arteaga CL, Engelman JA. Acquired resistance to EGFR tyrosine kinase inhibitors in cancer cells is mediated by loss of IGF-binding proteins. The Journal of clinical investigation. 2008; 118:2609-2619.

42. Yu L, Gu C, Zhong D, Shi L, Kong Y, Zhou Z, Liu S. Induction of autophagy counteracts the anticancer effect of cisplatin in human esophageal cancer cells with acquired drug resistance. Cancer Lett. 2014; 355:34-45.

43. Wei Y, Zou Z, Becker N, Anderson M, Sumpter R, Xiao G, Kinch L, Koduru P, Christudass CS, Veltri RW, Grishin NV, Peyton M, Minna J, et al. EGFR-mediated Beclin 1 phosphorylation in autophagy suppression, tumor progression, and tumor chemoresistance. Cell. 2013; 154:1269-1284.

44. Allen JE, Krigsfeld G, Patel L, Mayes PA, Dicker DT, Wu GS, El-Deiry WS. Identification of TRAIL-inducing compounds highlights small molecule ONC201/TIC10 as a unique anti-cancer agent that activates the TRAIL pathway. Molecular cancer. 2015; 14:99.

45. Allen JE, Krigsfeld G, Mayes PA, Patel L, Dicker DT, Patel AS, Dolloff NG, Messaris E, Scata KA, Wang W, Zhou JY, Wu GS, El-Deiry WS. Dual inactivation of Akt and ERK by TIC10 signals Foxo3a nuclear translocation, TRAIL gene induction, and potent antitumor effects. Science translational medicine. 2013; 5:171ra117.

46. Hanly EK, Tuli NY, Bednarczyk RB, Suriano R, Geliebter J, Moscatello AL, Darzynkiewicz Z, Tiwari RK. Hyperactive ERK and persistent mTOR signaling characterize vemurafenib resistance in papillary thyroid cancer cells. Oncotarget. 2016; 7:8676-8687. https://doi.org/10.18632/ oncotarget.6779.

47. Zhuang H, Bai J, Chang JY, Yuan Z, Wang P. MTOR inhibition reversed drug resistance after combination radiation with erlotinib in lung adenocarcinoma. Oncotarget. 2016; 7:84688-84694. https://doi.org/10.18632/ oncotarget.12423.

48. Wang A, Wu H, Chen $\mathrm{C}$, Hu C, Qi Z, Wang W, Yu K, Liu X, Zou F, Zhao Z, Wu J, Liu J, Liu F, et al. Dual inhibition of AKT/FLT3-ITD by A674563 overcomes 
FLT3 ligand-induced drug resistance in FLT3-ITD positive AML. Oncotarget. 2016; 7:29131-29142. https://doi. org/10.18632/oncotarget.8675.

49. Hodkinson PS, Elliott T, Wong WS, Rintoul RC, Mackinnon AC, Haslett C, Sethi T. ECM overrides DNA damageinduced cell cycle arrest and apoptosis in small-cell lung cancer cells through betal integrin-dependent activation of PI3-kinase. Cell death and differentiation. 2006; 13:1776-1788.

50. Aplin AE, Stewart SA, Assoian RK, Juliano RL. Integrinmediated adhesion regulates ERK nuclear translocation and phosphorylation of Elk-1. The Journal of cell biology. 2001; 153:273-282.

51. Kong L, Zhang P, Li W, Yang Y, Tian Y, Wang X, Chen S, Yang Y, Huang T, Zhao T, Tang L, Su B, Li F, et al. KDM1A promotes tumor cell invasion by silencing TIMP3 in non-small cell lung cancer cells. Oncotarget. 2016; 7:27959-27974. https://doi.org/10.18632/oncotarget.8563.

52. Trapnell C, Williams BA, Pertea G, Mortazavi A, Kwan G, van Baren MJ, Salzberg SL, Wold BJ, Pachter L. Transcript assembly and quantification by RNA-Seq reveals unannotated transcripts and isoform switching during cell differentiation. Nature biotechnology. 2010; 28:511-515.

53. Huang da W, Sherman BT, Lempicki RA. Systematic and integrative analysis of large gene lists using DAVID bioinformatics resources. Nature protocols. 2009; 4:44-57.

54. Huang T, Zhang P, Li W, Zhao T, Zhang Z, Chen S, Yang Y, Feng Y, Li F, Shirley Liu X, Zhang L, Jiang G, Zhang F. G9A promotes tumor cell growth and invasion by silencing CASP1 in non-small-cell lung cancer cells. Cell death \& disease. 2017; 8:e2726. 